\title{
Anatomía macroscópica y microscópica del sistema urogenital de la tortuga sabanera podocnemis vogli muller, 1935. (Testudines Pelomedusidae)
}

\author{
The macroscopic and microscopic anatomy of the urogenital \\ system of the Savannah side-necked turtle Podocnemis vogli \\ Muller, 1935 (Testudines Pelomedusidae)
}
Anatomia macroscópica e microscópica do sistema urogenital da tartaruga sabanera Podocnemis Vogli Muller, 1935. (Testudines-Pelomedusidae)

William J. Hernández-Henao (Q.E.P.D)'; José A. Rodríguez-Pulido², Jorge A. Astwood-Romero'

MVZ, Grupo de Estudio en Reptiles Federico Medem - Universidad de Los Llanos

Biologo, MSc, Grupo de investigación en Genética y Reproducción Animal (GIRGA), Universidad de los Llanos.

Email: jarodriguez@unillanos.edu.co:

Recibido: noviembre 19 de $2010 \quad$ Aceptado: marzo 15 de 2013

\begin{abstract}
Resumen
En este artículo, se describe la anatomía macroscópica y microscópica del sistema urogenital de la tortuga sabanera Podocnemis vogli (Testudines Pelomedusidae), para tal fin se utilizaron 10 ejemplares adultos (cinco machos y cinco hembras), clínicamente sanos procedentes del zoológico Bioparque los Ocarros de Villavicencio-Meta. Se sacrificaron los animales con Pentobarbital Sódico $31.4 \mathrm{mg} / \mathrm{kg}$ se realizó disección y estableció las relaciones morfométricas de los diferentes órganos. Se tomaron muestras de los órganos en formalina buferada para análisis histológico. Se identificó la presencia de riñones de tipo metanéfrico con numerosos glomérulos, que confluyen mediante uréteres a las bolsas cloacales, las dos estructuras estaban revestidas de un epitelio simple cúbico. Los oviductos presentaron estriaciones sin presencia de espermatecas, ni de ensanchamiento a manera de útero. El hemipene presento 5 secciones y una ranura uretral mediana la cual conforma un saco espermático. Los hallazgos macro y microscópicos son similares a los encontrados en reptiles y las pequeñas diferencias pueden estar relacionados con las características biológicas propias de la especie.
\end{abstract}

Palabras clave: Tortuga sabanera, Podocnemis vogli anatomía, histología, sistema urogenital

\section{Abstract}

This article describes the macroscopic and microscopic anatomy of the Podocnemis vogli (Testudines Pelomedusidae) Savannah side-necked turtle's urogenital system. Ten clinically healthy adult examples (five male and five females) were 
used for such purpose; they came from the Ocarros zoological bio-park near Villavicencio, in the Meta department. The animals were sacrificed with $31.4 \mathrm{mg} / \mathrm{Kg}$ pentobarbital sodium they were dissected and the different organs'morpho metricrelation ships were established. Samples were taken from the organs and placed in buffered formalin for histological analysis. Metanephric kidneys were identified, having numerous glomeruli converging via urethra to the cloacal bags; both structures were coated in a simple cuboidal epithelium. The oviducts had striations with out the presence of spermathecas, or widening like the uterus. The hemipene had 5 sections and a urethral groove forming aspermatic sack. The macro and microscopic findings were similar to those found in reptiles and the small differences could have been related to the species' biological characteristics.

Key words: Turtle, Savannah side-necked turtle Podocnemis vogli, anatomy, histology, urogenital system.

\begin{abstract}
Resumo
Neste artigo, vamos descreve-se a anatomia macro e microscópica do sistema urogenital da tartaruga (Sabanera Podocnemis Vogli (Testudines Pelomedusidae), para estefim foran utilizados 10 indivíduos adultos (cinco machos e cinco fêmeas), clinicamente sadios, procedentes do Bioparque Los Ocarros de Villavicencio -Meta. Os animais foram sacrificados com pentobarbital sódico 31,4 mg / kg foi realizada disseção e estabelecida as relações morfométricas dos diferentes órgãos. Foram tomadas amostras dos órgãos em formalina tamponada para análise histológica. Identificada a presença de rins do tipo metanéfrico numerosos glomérulos, que fluem através dos ureteres as bolsas cloacais as duas estruturas estavam revestidas de epitélio simples cúbico. Os oviductos não apresentaram a presença de estrias sem presencia de espermatecanem espalhamento na forma de útero. Os hemipénis apresentaram cinco seções e um sulco uretral meio que forma um saco de esperma. Os achados macroscópicos e microscópicos são semelhantes aos encontrados em répteis e pequenas diferenças podem estar relacionadas com as características biológicas da espécie.
\end{abstract}

Palavras chave: Tartarugas, sabanera Podocnemis Vogli, Anatomia, Histologia, sistema urogenital

\section{Introducción}

Colombia posee más del $14 \%$ de las especies de tortugas existentes en el mundo, la especie Podocnemis vogli es endémica de los Llanos Orientales colombianos y occidentales venezolanos. Dentro del género Podecnemis se clasifican 7 especies y Podecnemis vogli se ubica en el ápice II del CITIES (Honegger et al., 1985) que de acuerdo con los criterios de UICN la ubica en la categoría de casi amenazada (Castano-Mora y Medem, 2002). Diversos estudios se han realizado de su historia natural, hábitat, distribución y estado ecológico (Rueda y Rueda, 2003), sin embargo, las investigaciones de su morfofisiología son escasas.

El desconocimiento de la anatomía macroscópica y microscópica de la fauna silvestre y en especial de las tortugas, ha dificultado los planes de conservación y las alternativas productivas, lo cual ha impedido comprender la fisiología y en su momento la patología macroscópica y microscópica. Dicha situación en parte puede estar influenciada por la normatividad existente, el uso indiscriminado de dicho recurso y el valor genético y biológico de las mismas (Escandón, 2004).

Una revisión en las bases de datos de estudios anatómicos en quelonios dan cuenta de investigaciones en tortugas marinas (Wyneken, 2001), del morroco Geochelone carbonaria (Faria, 2003) y tortugas del mediterráneo (Oros, 2004), por lo que se evidencia una escasa investigación en este campo. Por lo anterior el objetivo de este estudio fue conocer la anatomía macroscópica y microscópica del sistema urogenital de la tortuga sabanera, lo cual permita comprende su fisiología y reproducción como base para orientar los programas de conservación.

\section{Materiales y métodos}

\section{Localización}

El trabajo se realizó en los Laboratorios de Biología e Histopatología de la Universidad de los Llanos, en el municipio de Villavicencio Km 4 vía Puerto López, vereda Barcelona, con las siguientes condiciones climatológicas medias anuales: temperatura promedio de $28^{\circ} \mathrm{C}$, precipitación anual de $4050 \mathrm{~mm}$, humedad relativa del $75 \%$ y una altura de $420 \mathrm{msnm}$.

\section{Animales Experimentales}

Se utilizaron 10 tortugas sabaneras (Podocnemis vogli) clínicamente sanas provenientes del Bioparque Los Ocarros, las hembras presentaban en promedio una longitud recta de caparazón (LRC) de $26.47 \mathrm{~cm}$ y los machos de $19.11 \mathrm{~cm}$. Los animales fueron mantenidos en cuarentena por 20 días en la Granja de la Universidad de los Llanos, Sede Barcelona, donde fueron alimentados con una dieta basada en concentrado para peces Proceal ${ }^{R} 28 \%$ (70\%) del Requerimiento energético diario (RED), Fruta (Banano, Mango) (20\% RED) y 
Bore (10\% RED) (Varela,2003. Dierenfeld, 1996), además fueron vermifugados con Levamisol a la dosis de 10 mg/Kg (Martínez, 1994).

Los animales fueron sacrificados mediante la técnica descrita por Close (1995) indicado para reptiles. El anestésico utilizado fue Pentobarbital sódico a la dosis de $31,4 \mathrm{mg} / \mathrm{kg}$ IM (Moon et al, 2001). Posterior a esto, se insertó una aguja afilada a través del foramen mágnum en la articulación atlanto occipital hasta la base del cerebro, para asegurar la rápida destrucción del mismo (Close, 1995). El análisis morfo métrico incluyó las medidas de longitud recta de caparazón (LRC), longitud de Plastrón (LP), Longitud de la sutura media ventral (SMV), Ancho de Caparazón (AC) y Peso (W) (Figura 1) Medem (1975).

El retiró del plastrón siguió la técnica descrita por Campbell (año) modificada por Chacón (2001), y consistió en cortar las uniones del puente, incidiendo las uniones de piel con el peto y retiro mediante disección roma en dirección cráneo caudal. A nivel de la zona pélvica con la ayuda de un martillo se fracturó el pubis ya que este se encontraba fusionado al plastrón por ser un animal del suborden Pleurodirae (Rueda y Rueda, 2003).

Se separó el paquete visceral del caparazón y se tomaron registros fotográficos con cámara Canon ® AS400 Photos hot, en un cuarto oscuro a una distancia de 40 $\mathrm{cm}$. Seguidamente se separaron los sistemas y se tomaron fotografías en las mismas condiciones anteriormente descritas. A los registros fotográficos se asignó un color para cada órgano teniendo como base la guía de colores de Microsoft $\AA^{\circledR}$, determinado por el programa ColorPic® 4.1, con el fin de obtener los colores de referencia normales y distinguir posibles estados patológicos por variación.

\section{Histología}

Las muestras para procesamiento histológico, se fijaron en formalina bufferada al $10 \%$, en una dilución 1:10 e incluidas en parafina. Se tomaron cubos de aproximadamente un centímetro de tejido, se realizados cortes con micrótomo de 3-5 $\mu \mathrm{m}$ y teñidos con hematoxilina-eosina (HyE) (Banks, 1996).

\section{Análisis estadístico}

Con la información obtenida se creó una base datos en Excell y analizada la información mediantes estadística descriptiva

\section{Resultados}

\section{Disposición anatómica de los órganos}

Los riñones se encontraron dorsalmente dentro de la cavidad celómica en contacto en su borde craneal con los pulmones, en la zona media con la aorta descendente, y su porción caudal con el caparazón, ventral a ellos se encontraron los intestinos. Se caracterizan por su forma angular, con los ángulos craneal y caudal más agudos, el ángulo obtuso medial, con presencia de un îleo donde ingresa la arteria renal y salen la vena y el uréter (Ur), internamente se aprecia un cáliz mayor (figuras 2 y 3 ). En las tablas 1 y 2 se presentan las relaciones alométricas de los riñones.

Color de Riñón. 533237

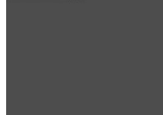

\section{Histología de los Riñones}

Los riñones presentaban dos zonas, una cortical externa (Der; Cz) y una medular (Md) en las cuales se evidencio la presencia del aparato yuxtaglomerular,
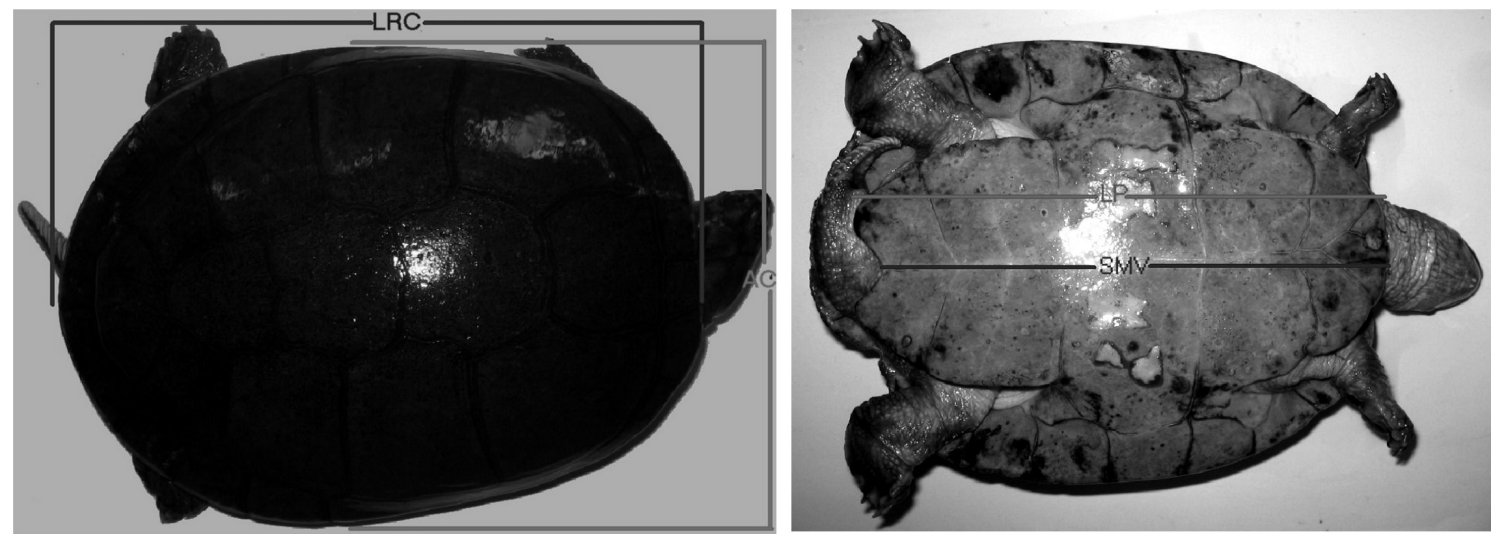

Figura 1. Morfometría: Longitud recta de Caparazón (LRC); Ancho de Caparazón (Ac); Longitud de plastrón (LP); Sutura media ventral (SMV) 


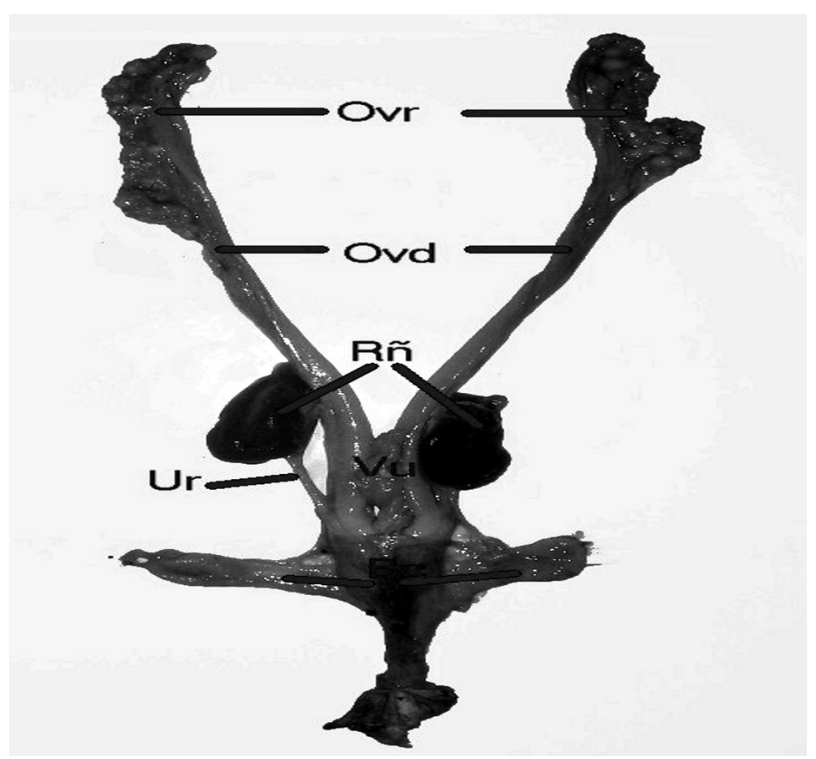

Figura 2: Sistema urogenital de una tortuga hembra; Ovr: Ovarios; Ovd: Oviductos; Rñ: Riñones; Ur: Ureter; Vu: Vejiga urinaria; $\mathrm{Bc}$ : Bolsas Cloacales

conformados por glomérulos (Gl) de un tamaño reducido, y una cápsula de bowman $(\mathrm{Cb})$ también reducida, estos glomérulos se encontraron en pocas cantidades, la cápsula de bowman posee un epitelio plano simple. Una característica importante fue la alta presencia de túbulos contorneados estrechos (Tb), con epitelio cúbico simple, que difieren de los colectores de mayor calibre y de las asas de Henle (AH). (Figura 4a, b).

\section{Uréteres}

Los uréteres presentaban forma cilíndrica y se ubican, mediales a los riñones de donde se originan, para descender caudoventralmente hasta insertarse en el borde dorsal de la vejiga urinaria.

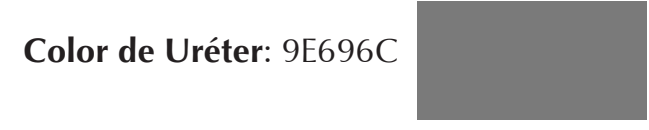

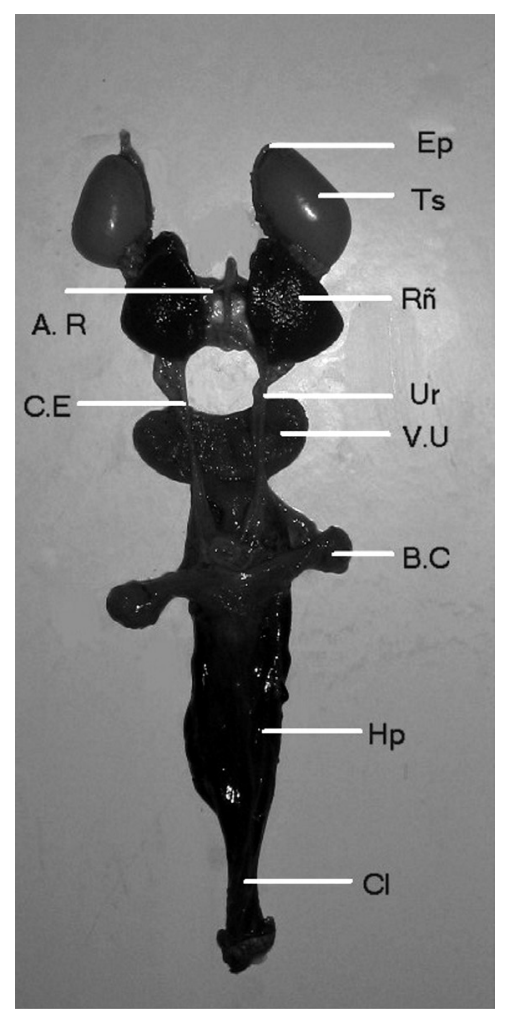

Figura 3: Sistema urogenital de un macho; Ep: Epidídimo; Ts: Testiculo; Rñ: Riñón; AR: Arteria Renal; Ur: Ureter; CE: Conducto espermático; VU: Vejiga urinaria; BC: Bolsa cloacal; Hp: pene; Cl:Cloaca.

\section{Histología de los Uréteres}

Los uréteres presentan un epitelio cúbico simple (Ecs) acompañados de tejido conectivo denso irregular (Al) y con una capa muscular (Msc) poco definida (Figura 5).

\section{Vejiga urinaria}

La ubicación de la vejiga urinaria cordiforme es ventral, su porción anterior esta en contacto dorsalmente con los intestinos y ventralmente con los músculos

Tabla 1. Relación porcentual alométrica de los riñones de la tortuga sabanera

\begin{tabular}{|c|c|c|c|c|c|c|c|c|c|c|}
\hline \multicolumn{9}{|c|}{ Riñón derecho } & \multicolumn{3}{c|}{ Riñón izquierdo } \\
\hline & L/LRC & L/Plastrón & L/SMV & AnO/An & PO/Pan & L/LRC & L/Plastrón & L/SMV & AnO/An & PO/Pan \\
\hline & $14,63 \pm 1,74$ & $15,80 \pm 2,07$ & $16,33 \pm 2,17$ & $11,85 \pm 0,83$ & $0,26 \pm 0,04$ & $14,05 \pm 1,57$ & $15,16 \pm 1,75$ & $15,66 \pm 1,78$ & $12,16 \pm 1,01$ & $0,25 \pm 0,04$ \\
\hline$\sigma^{\pi}$ & $13,74 \pm 1,42$ & $15,42 \pm 1,59$ & $16,29 \pm 1,71$ & $11,46 \pm 1,97$ & $0,21 \pm 0,06$ & $14,66 \pm 3,72$ & $16,46 \pm 4,17$ & $17,39 \pm 4,46$ & $11,00 \pm 1,39$ & $0,22 \pm 0,03$ \\
\hline Total & $14,18 \pm 1,57$ & $15,61 \pm 1,75$ & $16,31 \pm 1,84$ & $11,65 \pm 1,44$ & $0,24 \pm 0,06$ & $14,36 \pm 2,71$ & $15,81 \pm 3,09$ & $16,53 \pm 3,33$ & $11,58 \pm 1,29$ & $0,23 \pm 0,03$ \\
\hline
\end{tabular}

L/LRC: Largo Riñón / Longitud Recta de Caparazón * 100; L/Plastrón: Largo Riñón / Longitud de Plastrón; L/SMV: Largo Riñón / Sutura Media Ventral; AnO/An: Ancho Riñón / Ancho animal * 100; PO/Pan: Peso Riñón / Peso animal * 100 

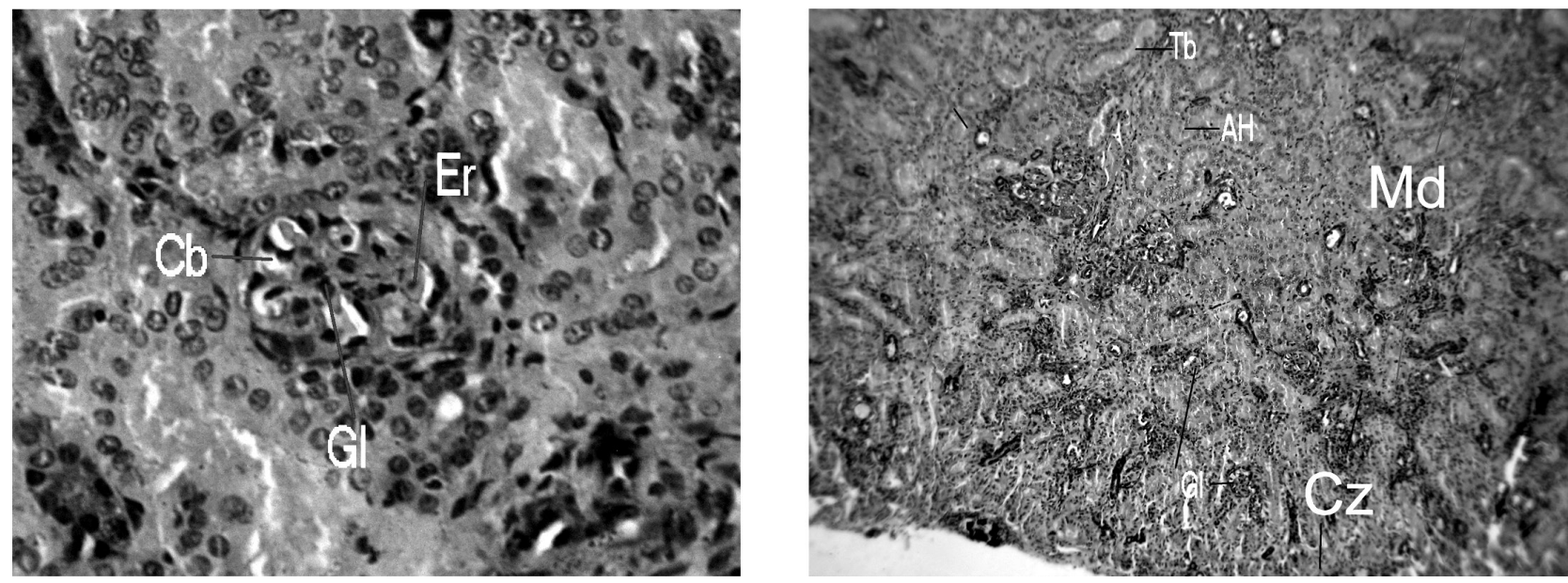

Figura 4a. Corte histológico del riñón: aparato Yuxtaglomerular 40X Figura 4b. Corte histológico del riñón: Parénquima renal 4X

abdominales, teniendo su inserción en la cloaca sobre el pubis. Se caracteriza por tener una pared elástica la cual se encontró dilatada y con contenido líquido.

\section{Color de Vejiga urinaria: 9E5953}

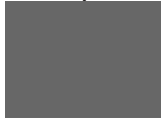

\section{Histología de la vejiga}

La vejiga está conformada por epitelio de transición (Et), con agregados linfoides (Al), este epitelio se organiza en pliegues vesicales $(\mathrm{Pg})$ debido al estado de la vejiga. Entre el tejido conectivo denso irregular se exhiben fibras de musculatura lisa (MI) (Figura 6). La relación porcentual alométrica de la vejiga se observan en la tabla 3.

Los ovarios se encontraron en diferentes estados, algunos con folículos y ovocitos, simulando racimos de uvas. Se ubican en los planos laterales de la cavidad celómica, cranealmente estan en contacto con los pulmones, donde el izquierdo limita con el borde caudal del lóbulo lateral izquierdo del hígado, medialmente con los intestinos, lateralmente con los oviductos y con las paredes del celoma (Figura 7). La relación porcentual alométrica de los ovarios se observan en la tabla 4 .

\section{Color de Ovarios: CF723A}

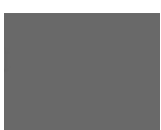

\section{Histología de Ovarios}

En el corte histológico de los ovarios se observaron dos zonas una cortical y una medular difusa, en los ovocitos se identificó una teca interna ( $\mathrm{TI}$ ) y una externa (TE) acompañados de la región germinal con células germinales, organizadas sobre un tejido conectivo denso irregular, tejido aerolar laxo y tejido adiposo (TA). (Figura 8)

\section{Oviducto}

Los oviductos se encuentran en las pociones laterales del tercer tercio del celoma, estando medialmente con los ovarios cranealmente y con los intestinos en su porción media, se dirigien caudo medial hasta insertarse en la base de la cloaca (Figura 9). La relación

Tabla 2. Relación porcentual alométrica de los uréteres de la tortuga sabanera

\begin{tabular}{|c|c|c|c|c|c|c|c|c|c|c|}
\hline \multicolumn{6}{|c|}{ Ureter derecho } & \multicolumn{5}{|c|}{ Uréter izquierdo } \\
\hline & L/LRC & L/Plastrón & L/SMV & $\mathrm{AnO} / \mathrm{An}$ & $\mathrm{PO} / \mathrm{Pan}$ & L/LRC & L/Plastrón & L/SMV & $\mathrm{AnO} / \mathrm{An}$ & $\mathrm{PO} / \mathrm{Pan}$ \\
\hline$q$ & $10,60 \pm 2,16$ & $11,46 \pm 2,46$ & $11,86 \pm 2,6$ & $1,65 \pm 0,33$ & $0,01 \pm 0,00$ & $11,90 \pm 2,84$ & $12,87 \pm 3,21$ & $13,33 \pm 3,39$ & $1,47 \pm 0,46$ & $0,01 \pm 0,00$ \\
\hline$\pi$ & $18,67 \pm 5,05$ & $20,95 \pm 5,6$ & $22,12 \pm 5,89$ & $1,52 \pm 0,56$ & $0,02 \pm 0,01$ & $17,68 \pm 4,41$ & $19,81 \pm 4,68$ & $20,95 \pm 5,12$ & $1,34 \pm 0,34$ & $0,02 \pm 0,01$ \\
\hline Total & $14,63 \pm 5,61$ & $16,20 \pm 6,45$ & $16,99 \pm 6,91$ & $1,59 \pm 0,44$ & $0,01 \pm 0,01$ & $14,79 \pm 4,64$ & $16,34 \pm 5,26$ & $17,14 \pm 5,74$ & $1,40 \pm 0,39$ & $0,01 \pm 0,01$ \\
\hline
\end{tabular}

L/LRC: Largo Uréter / Longitud Recta de Caparazón * 100; L/Plastrón: Largo Uréter / Longitud de Plastrón; L/SMV: Largo Uréter / Sutura Media Ventral; AnO/An: Ancho Uréter derecho / Ancho animal * 100; PO/Pan: Peso Uréter derecho / Peso animal * 100 


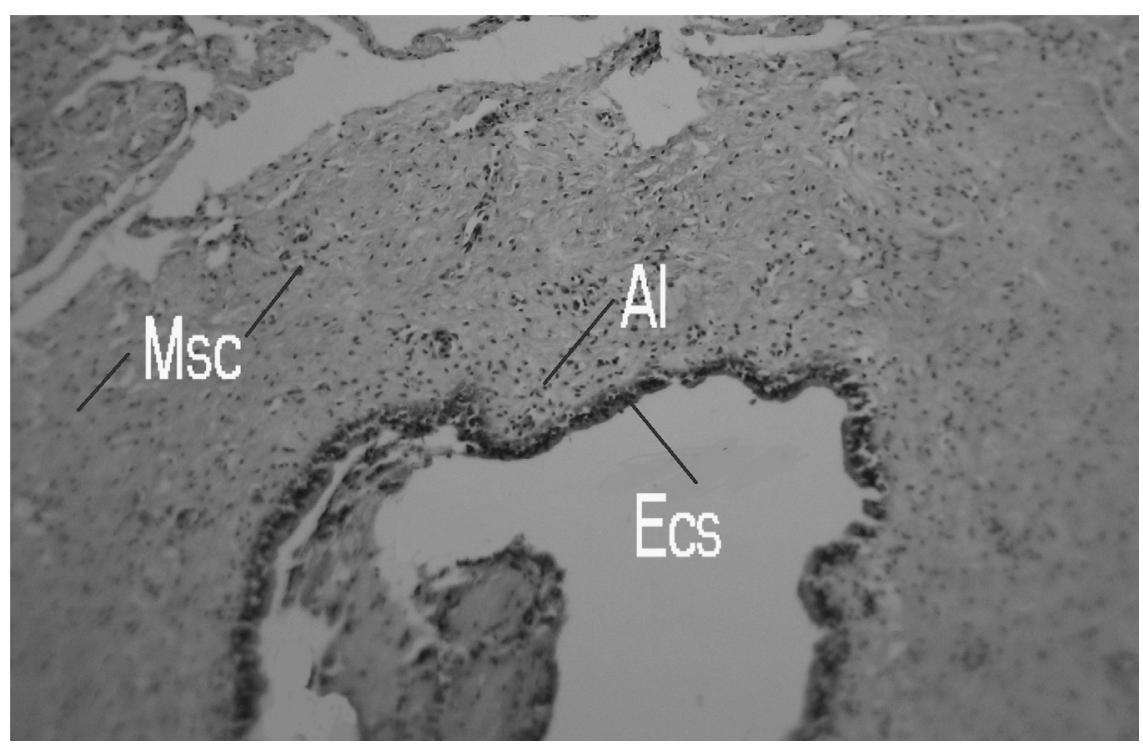

Figura 5: Corte histológico de Uréter $4 \mathrm{X}$

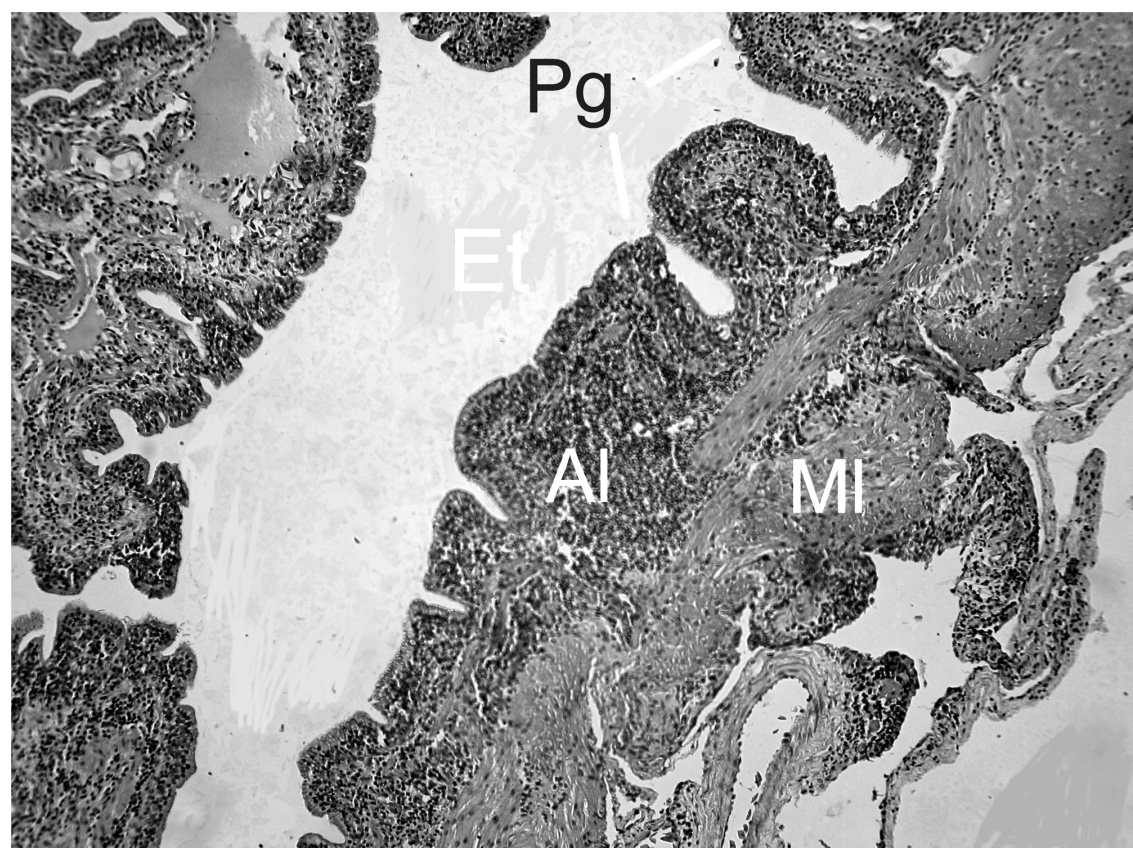

Figura 6: Corte histológico de vejiga urinaria $4 \mathrm{X}$

Tabla 3. Relación porcentual alométrica vejiga urinaria en la tortuga sabanera

\begin{tabular}{|c|c|c|c|c|c|}
\hline \multicolumn{7}{|c|}{ Vejiga urinaria } \\
\hline & L/LRC & L/Plastrón & L/SMV & AnO/An & PO/Pan \\
\hline+ & $15,85 \pm 3,02$ & $17,08 \pm 3,08$ & $17,62 \pm 2,96$ & $28,23 \pm 4,38$ & $0,18 \pm 0,03$ \\
\hline \multirow{\gamma}{*}{ Total } & $19,17 \pm 3,86$ & $21,47 \pm 4,10$ & $22,72 \pm 4,51$ & $32,29 \pm 5,18$ & $0,20 \pm 0,05$ \\
\hline
\end{tabular}

L/LRC: Largo Vejiga urinaria / Longitud Recta de Caparazón * 100; L/Plastrón: Largo Vejiga urinaria / Longitud de Plastrón; L/SMV: Largo Vejiga urinaria / Sutura Media Ventral; AnO/An: Ancho Vejiga urinaria / Ancho animal * 100; PO/Pan: Peso Vejiga urinaria / Peso animal * 100 
porcentual alométrica de los oviductos se observan en la tabla 5.

\section{Color de Oviducto: BE9383}

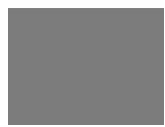

\section{Histología de Oviducto}

El epitelio del oviducto es cilíndrico pseudoestratificado (Ep) con presencia de células caliciformes, y una zona luminal altamente irrigada (Zi), bajo el epitelio hay un tejido conjuntivo denso irregular y una capa muscular lisa gruesa (Msc). (Figura 10)

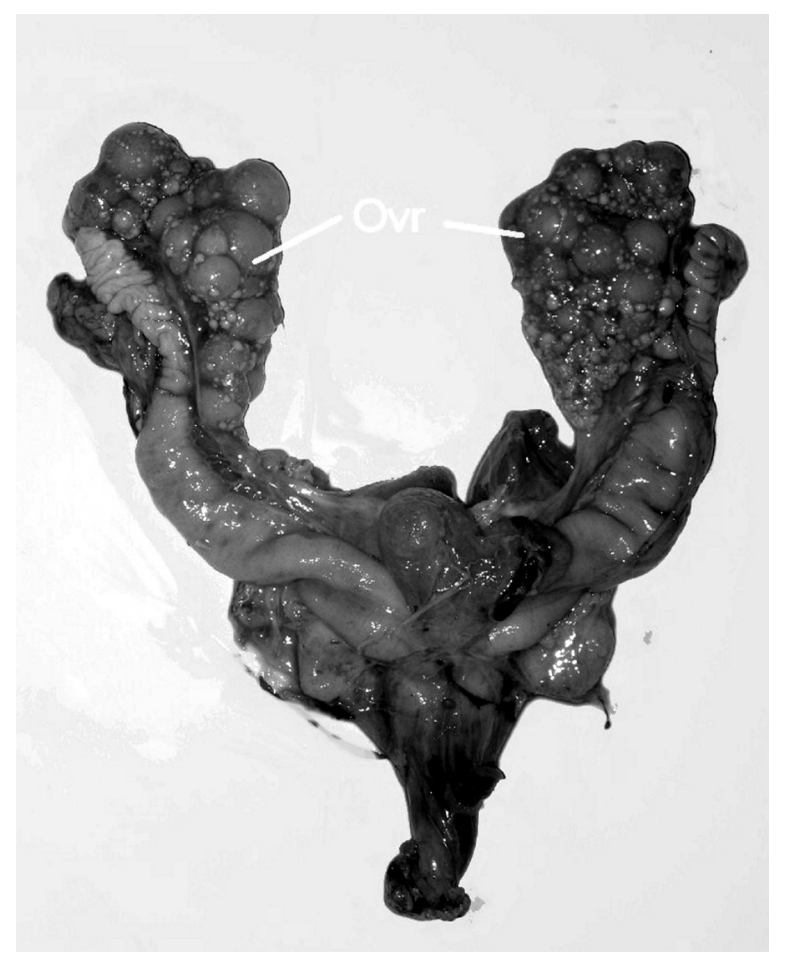

Figura 7. Ovarios: Ovr

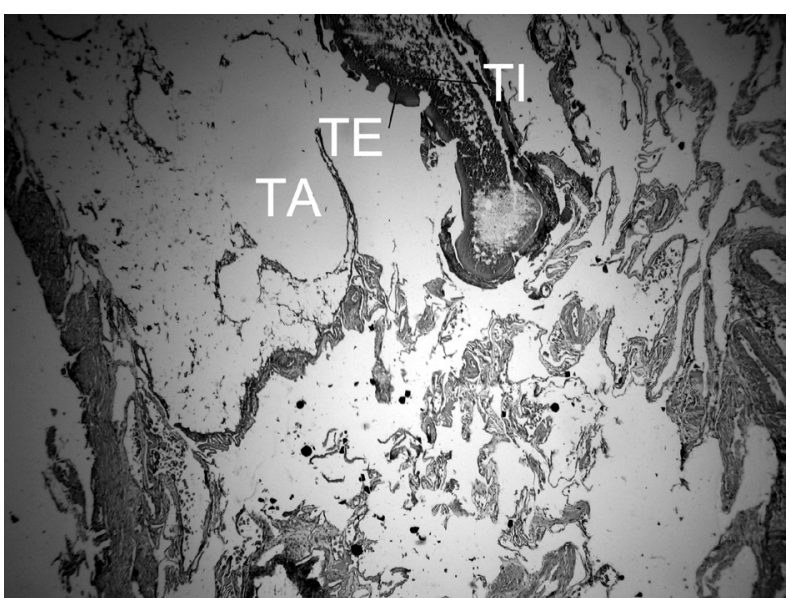

Figura 8: Corte histológico del ovario

\section{Testículos}

Los testículos presentaban forma ovalada, se ubicaban en el tercer tercio de la cavidad celómica. El testículo derecho se encuentra dorsal al intestino anterior y ventral al riñón correspondiente, cranealmente limita con la primer asa del intestino anterior, el izquierdo se

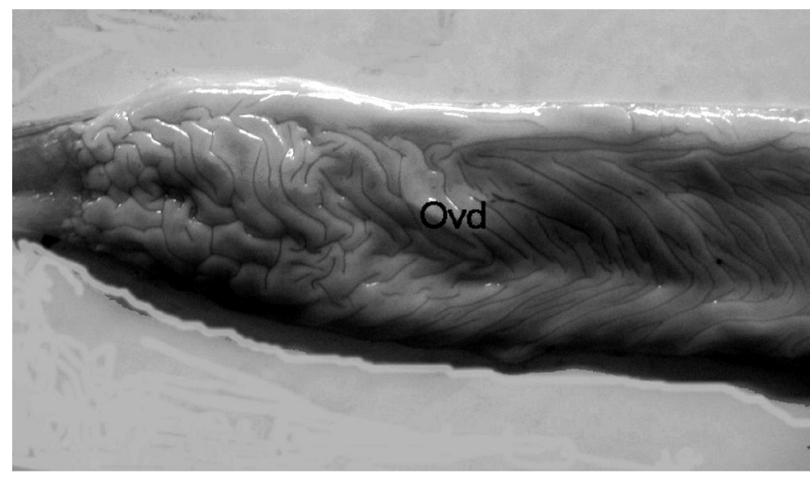

Figura 9: Oviducto: Ovd. Se aprecian los pliegues de oviducto

Tabla 4. Relación porcentual alométrica de los ovarios de la tortuga sabanera

\begin{tabular}{|c|c|c|c|c|c|c|c|c|c|c|}
\hline \multicolumn{9}{|c|}{ Ovario derecho } & \multicolumn{5}{c|}{ Ovario izquierdo } \\
\hline \multirow{2}{*}{+} & L/LRC & L/Plastrón & L/SMV & AnO/An & PO/Pan & L/LRC & L/Plastrón & L/SMV & AnO/An & PO/Pan \\
\hline & $45,01 \pm$ & $48,59 \pm$ & $50,25 \pm$ & $17,49 \pm$ & $1,47 \pm$ & $42,43 \pm$ & $45,77 \pm$ & $47,36 \pm$ & $21,81 \pm$ & $1,57 \pm$ \\
& 10,57 & 11,56 & 12,17 & 7,87 & 1,08 & 11,7 & 12,59 & 13,29 & 9,56 & 1,42 \\
\hline
\end{tabular}

L/LRC: Largo Ovario / Longitud Recta de Caparazón * 100; L/Plastrón: Largo Ovario / Longitud de Plastrón; L/SMV: Largo Ovario / Sutura Media Ventral; AnO/An: Ancho Ovario / Ancho animal * 100; PO/Pan: Peso Ovario / Peso animal * 100 
Tabla 5. Relación porcentual alométrica de los oviductos de la tortuga sabanera

\begin{tabular}{|c|c|c|c|c|c|c|c|c|c|c|}
\hline \multicolumn{9}{|c|}{ Oviducto derecho } & \multicolumn{4}{c|}{ Oviducto izquierdo } \\
\hline & L/LRC & L/Plastrón & L/SMV & AnO/An & PO/Pan & L/LRC & L/Plastrón & L/SMV & $\begin{array}{c}\text { AnO/ } \\
\text { An }\end{array}$ & $\begin{array}{c}\text { PO/ } \\
\text { Pan }\end{array}$ \\
\hline+ & $\begin{array}{c}167,11 \pm \\
46,48\end{array}$ & $\begin{array}{c}180,14 \pm \\
49,79\end{array}$ & $\begin{array}{c}186,09 \pm \\
51,54\end{array}$ & $\begin{array}{c}7,13 \pm \\
1,02\end{array}$ & $0,62 \pm 0,3$ & $\begin{array}{c}154,52 \\
\pm 43\end{array}$ & $\begin{array}{c}166,52 \\
\pm 46,03\end{array}$ & $\begin{array}{c}171,86 \\
\pm 46,92\end{array}$ & $\begin{array}{c}6,47 \pm \\
2,87\end{array}$ & $\begin{array}{c}0,62 \pm \\
0,33\end{array}$ \\
\hline
\end{tabular}

L/LRC: Largo Oviducto / Longitud Recta de Caparazón * 100; L/Plastrón: Largo Oviducto / Longitud de Plastrón; L/SMV: Largo Oviducto / Sutura Media Ventral; AnO/An: Ancho Oviducto / Ancho animal * 100; PO/Pan: Peso Oviducto / Peso animal * 100

encuentra caudal al lóbulo izquierdo visceral del hígado, ventralmente queda en contacto con la membrana celomática, ambos testículos medialmente limitan con los riñones.

\section{Color de Testículo: 9C765F}

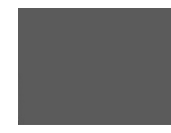

\section{Histología de Testículo}

Los testículos están conformados por los túbulos seminíferos (Ts), en su lámina basal se encuentran las

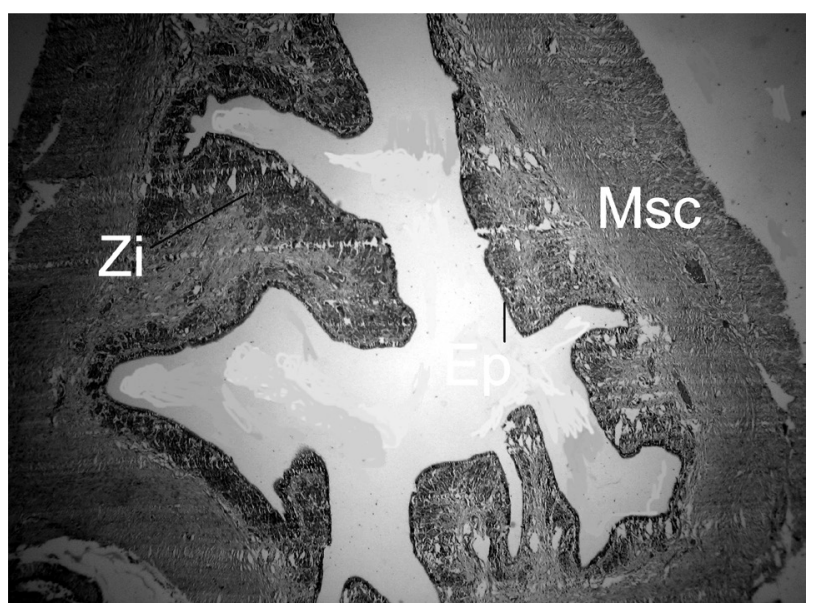

Figura 10: Corte histológico de oviducto $4 \mathrm{X}$ espermatogonias (Eg) que se van acercando a la luz hasta encontrar los espermatocitos (Es), ubicados en la capa germinal y adyacente a estas las células de Sertoli (Cs), estos túbulos están circundados por poco tejido conectivo y en su intersticio de ubican las células de Leyding $(\mathrm{CL})$, el testículo está recubierto por una túnica albugínea (Figura 11a,b). La relación porcentual alométrica de los testículos se observan en la tabla 6 .

\section{Epidídimo}

Los epidídimos se originan en el polo craneal de los testículos, se dirigen por su porción medial hasta separarse de estos en el borde caudal, se caracterizan por estar enrrollados y al separarse de los testículos se liberan para pasar a los conductos espermáticos.

\section{Color de Epidídimo: BAA291}

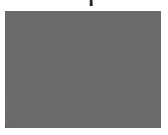

\section{Histología del Epidídimo}

El epidídimo está compuesto por un epitelio cilíndrico ciliado pseudoestratificado (Ep), al cual llega la red de testis (Rt), que esta conformada por un epitelio simple cúbico, estas estructuras están circundadas por fibras musculares (Msc) y tejido denso irregular. El epidídimo esta cubierto por una túnica albugínea (Figura 12). La relación porcentual alométrica de los epidídimos se observan en la tabla 7.

Tabla 6. Relación porcentual alométrica de los testículos de la tortuga sabanera

\begin{tabular}{|c|c|c|c|c|c|c|c|c|c|c|}
\hline \multicolumn{6}{|c|}{ Testículo derecho } & \multicolumn{5}{|c|}{ Testículo izquierdo } \\
\hline & L/LRC & L/Plastrón & L/SMV & AnO/An & PO/Pan & L/LRC & L/Plastrón & L/SMV & AnO/An & PO/Pan \\
\hline$\sigma^{\lambda}$ & $\begin{array}{c}10,62 \pm \\
2,81\end{array}$ & $\begin{array}{c}11,95 \pm \\
3,25\end{array}$ & $\begin{array}{c}12,61 \\
\pm 3,39\end{array}$ & $\begin{array}{c}8,13 \pm \\
2,82\end{array}$ & $\begin{array}{c}0,15 \pm \\
0,07\end{array}$ & $\begin{array}{c}10,82 \pm \\
2,76\end{array}$ & $\begin{array}{c}12,17 \pm \\
3,16\end{array}$ & $\begin{array}{c}12,84 \pm \\
3,27\end{array}$ & $\begin{array}{c}9,02 \pm \\
2,06\end{array}$ & $\begin{array}{c}0,17 \\
\pm 0,07\end{array}$ \\
\hline
\end{tabular}

L/LRC: Largo Testículo / Longitud Recta de Caparazón * 100; L/Plastrón: Largo Testículo / Longitud de Plastrón; L/SMV: Largo Testículo / Sutura Media Ventral; AnO/An: Ancho Testículo / Ancho animal * 100; PO/Pan: Peso Testículo / Peso animal * 100 


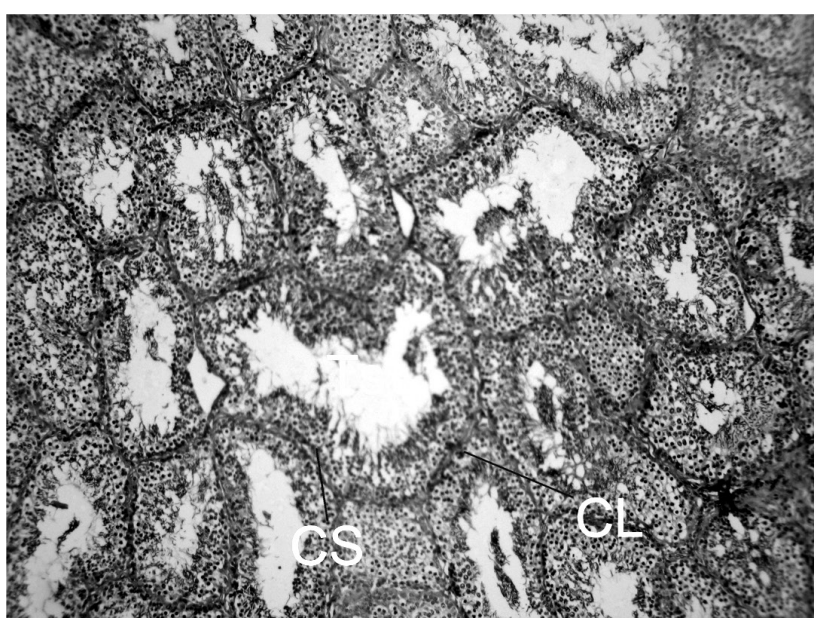

Figura 11a. Corte histológico del testículo:

Parénquima testicular $4 \mathrm{X}$

\section{Los conductos deferentes}

Los conductos deferentes presentaban forma cilíndrica, se originan en los epidídimos, y se insertan en la base del hemipene, en contacto con la vejiga ventral a ellos.

\section{Color de Cond. deferente: AE7976}

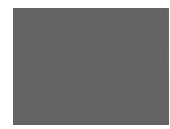

Histología del Conducto deferente

El conducto espermático o deferente está conformado por un tubo central y otros anexos (Tacc), con epitelio cúbico simple (Ep), recubiertos por tejido muscular liso (Msc) y por tejido conjuntivo, recubiertos por una túnica albugínea (Ta) (Figura 13). La relación porcentual alométrica de los conductos deferentes se observan en la tabla 8.

\section{El pene}

El pene presenta forma cuneiforme, se encuentra alojado en la zona ventral de la cloaca, se caracteriza por tener cinco porciones: dos craneales alargadas (1), dos medias (2) que se dilatan respecto a las anteriores y

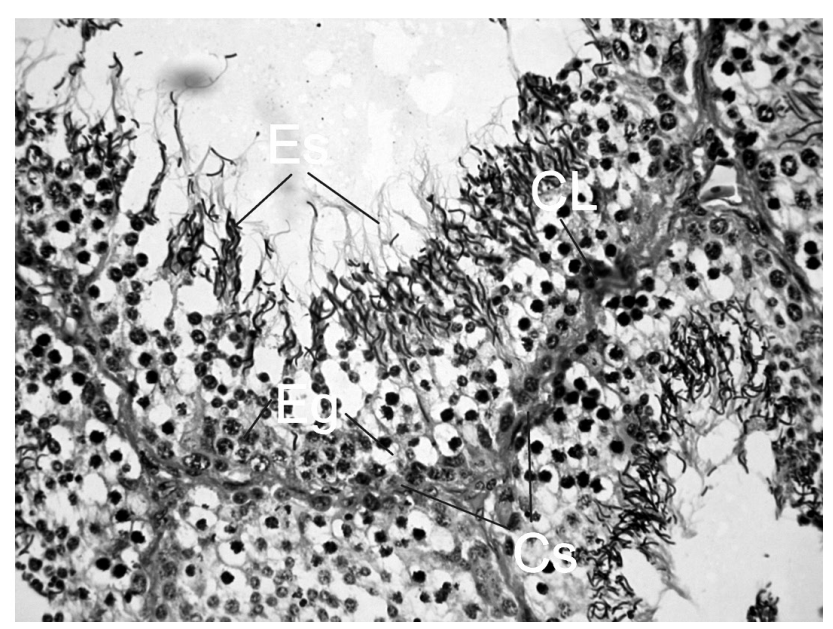

Figura 11b. Corte histológico del testículo: células germinales y fases germinativas

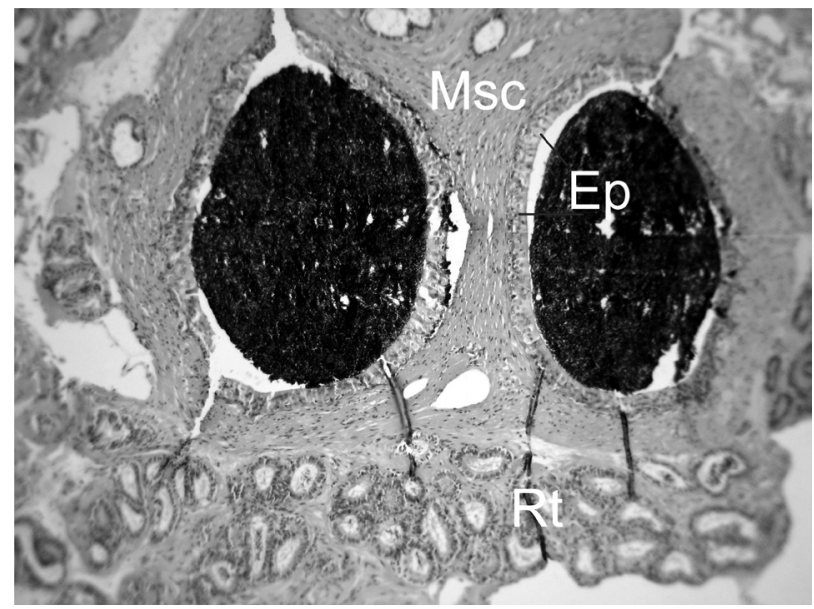

Figura 12. Corte histológico de epidídimo; en la zona superior se encuentra el epidídimo y en la inferior la red de testis.

una caudal triangular (3), se aprecian orificio en esta última porción (Figura 14). La relación alométrica del pene se observa en la tabla 9.

Color de pene: $4 \mathrm{~B} 4747$

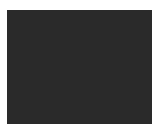

Tabla 7. Relación porcentual alométrica de los epidídimos de la tortuga sabanera

\begin{tabular}{|c|c|c|c|c|c|c|c|c|c|c|}
\hline \multicolumn{6}{|c|}{ Epididimo derecho } & \multicolumn{5}{|c|}{ Epididimo izquierdo } \\
\hline & L/LRC & L/Plastr & L/SMV & $\mathrm{AnO} / \mathrm{An}$ & $\mathrm{PO} / \mathrm{Pan}$ & L/LRC & L/Plastrón & L/SMV & $\mathrm{AnO} / \mathrm{An}$ & PO/Pan \\
\hline$\hat{0}$ & $\begin{array}{r}25,56 \\
\pm 7,15\end{array}$ & $\begin{array}{r}28,78 \\
\pm 8,33\end{array}$ & $\begin{array}{r}30,36 \\
\pm 8,68\end{array}$ & $\begin{array}{c}3,53 \pm \\
0,95\end{array}$ & $\begin{array}{c}0,03 \pm \\
0,01\end{array}$ & $\begin{array}{r}28,85 \\
\pm 9,06\end{array}$ & $\begin{array}{c}32,49 \pm \\
10,47\end{array}$ & $\begin{array}{c}34,23 \pm \\
10,77\end{array}$ & $\begin{array}{c}3,51 \pm \\
1,54\end{array}$ & $\begin{array}{c}0,04 \pm \\
0,02\end{array}$ \\
\hline
\end{tabular}

L/LRC: Largo Epidídimo / Longitud Recta de Caparazón * 100; L/Plastrón: Largo Epidídimo / Longitud de Plastrón; L/SMV: Largo Epidídimo / Sutura Media Ventral; AnO/An: Ancho Epidídimo / Ancho animal * 100; PO/Pan: Peso Epidídimo / Peso animal * 100 
Tabla 8. Relación porcentual alométrica de los conductos deferentes de la tortuga sabanera.

\begin{tabular}{|c|c|c|c|c|c|c|c|c|c|c|}
\hline \multicolumn{6}{|c|}{ Conducto deferente derecho } & \multicolumn{5}{|c|}{ Conducto deferente izquierdo } \\
\hline \pm & L/LRC & $\begin{array}{c}\text { L/ } \\
\text { Plastrón }\end{array}$ & L/SMV & AnO/An & PO/Pan & L/LRC & $\begin{array}{c}\text { L/ } \\
\text { Plastrón }\end{array}$ & L/SMV & AnO/An & $\mathrm{PO} / \mathrm{Pan}$ \\
\hline$\widehat{\sigma}$ & $\begin{array}{r}12,33 \\
\pm 1,65\end{array}$ & $\begin{array}{r}13,82 \\
\pm 1,64\end{array}$ & $\begin{array}{c}14,61 \\
\pm 1,81\end{array}$ & $\begin{array}{c}1,36 \pm \\
0,35\end{array}$ & $\begin{array}{c}0,01 \pm \\
0,00\end{array}$ & $\begin{array}{r}12,26 \\
\pm 2,65\end{array}$ & $\begin{array}{l}13,79 \\
\pm 3,2\end{array}$ & $\begin{array}{r}14,54 \\
\pm 3,19\end{array}$ & $\begin{array}{c}1,31 \pm \\
0,41\end{array}$ & $\begin{array}{c}0,01 \pm \\
0,00\end{array}$ \\
\hline
\end{tabular}

L/LRC: Largo Conducto deferente / Longitud Recta de Caparazón * 100; L/Plastrón: Largo Conducto deferente / Longitud de Plastrón; L/SMV: Largo Conducto deferente / Sutura Media Ventral; AnO/An: Ancho Conducto deferente / Ancho animal * 100; PO/Pan: Peso Conducto deferente / Peso animal * 100

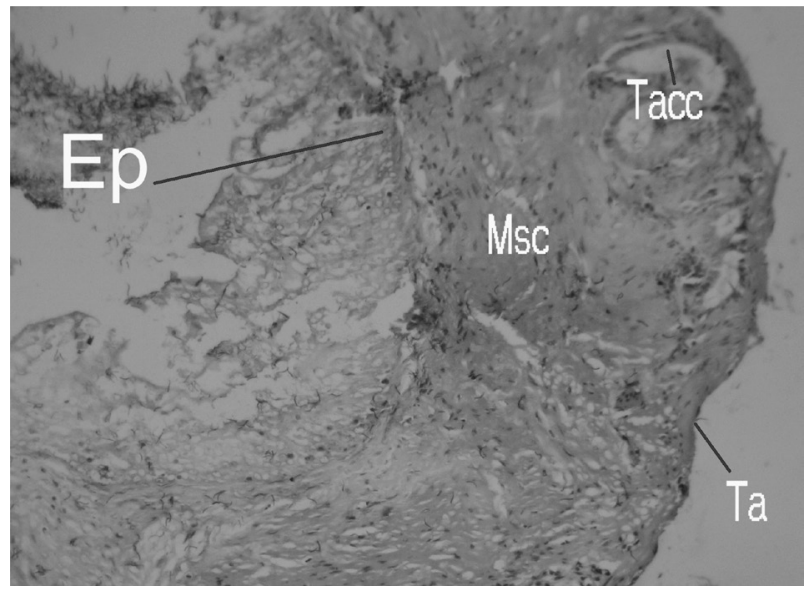

Figura 13. Corte histológico del conducto deferente $4 \mathrm{X}$

\section{Histología de pene}

El pene se encuentra recubierto por una túnica albugínea (Ta), la cual alberga músculo liso $(\mathrm{ML})$ y tejido conjuntivo denso irregular, presentando tabiques, el cual se encuentra con zonas vascularizadas (Zv) acompañadas de fibras colágenas y elásticas. Los cuerpos cavernosos poseen epitelio plano simple no queratinizado (Figura 15).

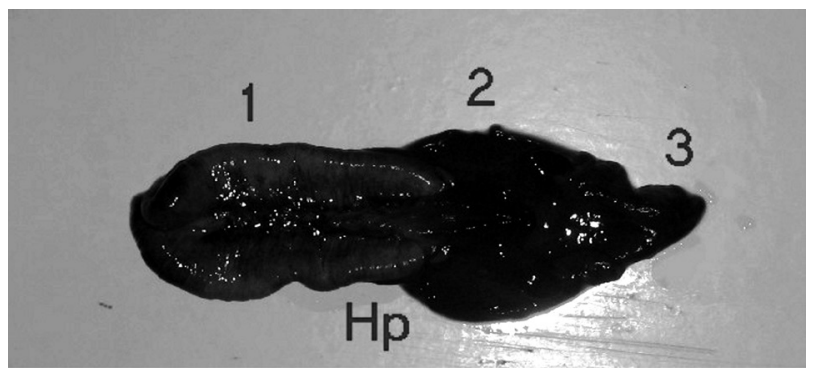

Figura 14. Pene: Porción anterior (1); Porción media (2); Porción posterior (3)
Tabla 9. Relación porcentual alométrica del pene macho de la tortuga sabanera

\begin{tabular}{|c|c|c|c|c|c|}
\hline \multicolumn{6}{|c|}{ Pene } \\
\hline & $\begin{array}{c}\text { L/LRC } \\
(\%)\end{array}$ & $\begin{array}{c}\text { L/Plastrón } \\
(\%)\end{array}$ & $\begin{array}{c}\text { L/SMV } \\
(\%)\end{array}$ & $\begin{array}{c}\text { AnO/An } \\
(\%)\end{array}$ & $\begin{array}{c}\text { PO/Pan } \\
(\%)\end{array}$ \\
\hline \multirow{2}{*}{$\begin{array}{c}\text { (\%) } \\
\text { (\%,64 }\end{array}$} & $\begin{array}{c}45,63 \pm \\
\pm 2,01\end{array}$ & $\begin{array}{c}48,19 \\
\pm 2,33\end{array}$ & $\begin{array}{c}15,37 \pm \\
3,98\end{array}$ & $\begin{array}{c}0,57 \pm \\
0,13\end{array}$ \\
\hline
\end{tabular}

L/LRC: Largo pene / Longitud Recta de Caparazón * 100; L/Plastrón: Largo pene / Longitud de Plastrón; L/SMV: Largo pene / Sutura Media Ventral; AnO/An: Ancho pene / Ancho animal * 100; PO/Pan: Peso pene / Peso animal * 100

\section{Las bolsas cloacales}

Se ubican lateralmente a la cloaca y mantienen contacto con los músculos abdominales, se caracterizan por ser dos sacos los cuales se insertan en la cloaca. (Figura 16). La relación porcentual alométrica de la bolsa cloacal se observa en la tabla 10.

\section{Color de Bolsa cloacal: A67169}

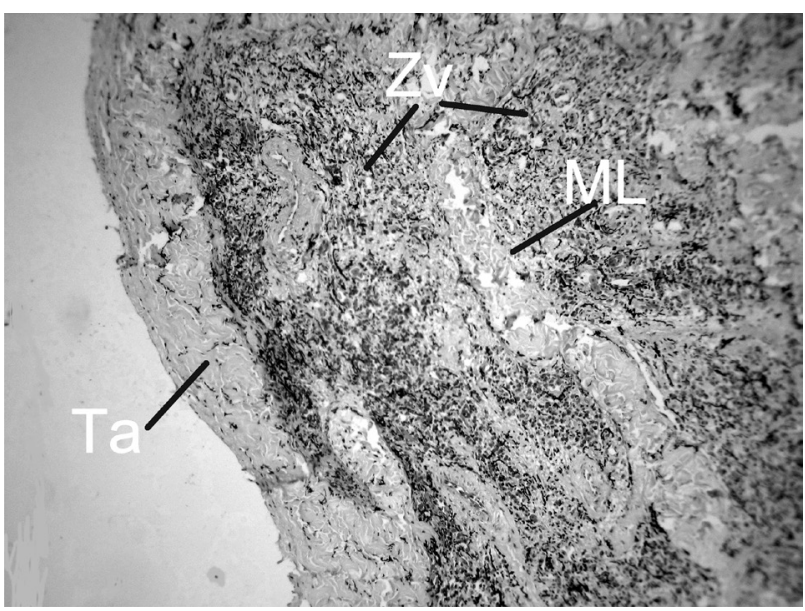

Figura 15. Corte histológico de pene $4 \mathrm{X}$ 


\section{Histología de la Bolsa Cloacal}

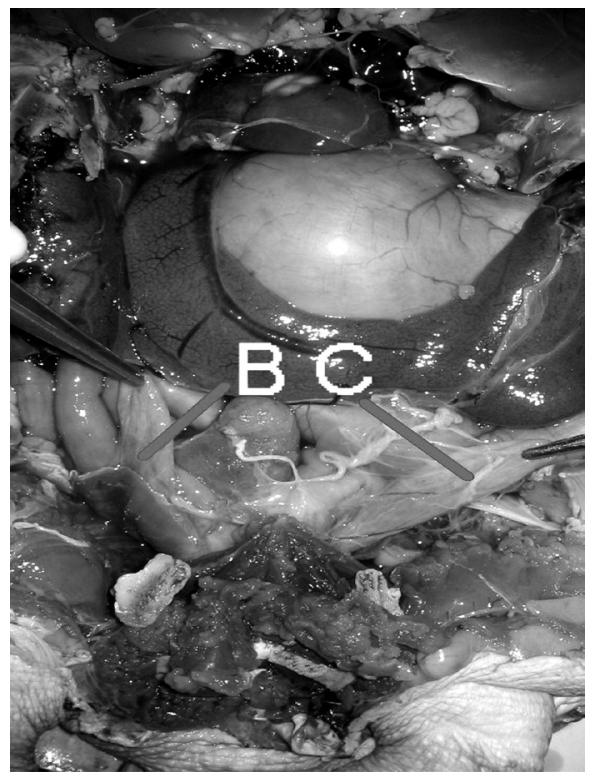

Figura 16. Bolsas cloacales (BC)
Las bolsas cloacales tienen un epitelio cilíndrico simple (EpT) sobre una lamina propia (Lp) y una túnica muscular de la mucosa (Ms m), en esta mucosa se encuentra gran cantidad de tejido linfoide $(\mathrm{AL})$, además se encuentra musculatura lisa $(\mathrm{ML})$ y se recubre por una lámina serosa (S). (Figura 17).

\section{La cloaca}

La cloaca se aloja sobre el pubis y dentro de la cintura pélvica, se prolonga dentro de la cola, tiene forma cilíndrica y en su porción anterior aloja el urodeo proveniente de la vejiga urinaria, el coprodeo proveniente del intestino posterior, y las bolsas cloacales.

\section{Color de Cloaca: 43423E}

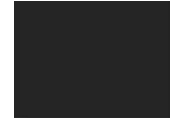

\section{Histología de Cloaca}

La cloaca posee una mucosa con epitelio cilíndrico pseudoestratificado (Ecp) con células caliciformes (Cc) en las últimas porciones pasa a ser plano estratificado, la submucosa $(\mathrm{Smc}$ ) contiene bastante tejido linfoide y

Tabla 10. Relación porcentual alométrica de bolsa cloacal

\begin{tabular}{|c|c|c|c|c|c|c|c|c|c|c|}
\hline \multicolumn{6}{|c|}{ Bolsa cloacal derecha } & \multicolumn{5}{|c|}{ Bolsa cloacal izquierda } \\
\hline & L/LRC & L/Plastrón & L/SMV & $\mathrm{AnO} / \mathrm{An}$ & PO/Pan & L/LRC & L/Plastrón & L/SMV & $\mathrm{AnO} / \mathrm{An}$ & PO/Pan \\
\hline q & $\begin{array}{c}6,68 \pm \\
0,94\end{array}$ & $\begin{array}{c}7,21 \pm \\
1,06\end{array}$ & $\begin{array}{c}7,45 \pm \\
1,15\end{array}$ & $\begin{array}{c}28,82 \pm \\
4,51\end{array}$ & $\begin{array}{c}0,10 \pm \\
0,03\end{array}$ & $\begin{array}{c}6,24 \pm \\
0,8\end{array}$ & $\begin{array}{c}6,75 \pm \\
0,98\end{array}$ & $\begin{array}{c}6,98 \pm \\
1,08\end{array}$ & $\begin{array}{c}28,06 \pm \\
8,46\end{array}$ & $\begin{array}{c}0,09 \pm \\
0,02\end{array}$ \\
\hline$\widehat{0}$ & $\begin{array}{c}5,75 \pm \\
0,85\end{array}$ & $\begin{array}{c}6,47 \pm \\
1,02\end{array}$ & $\begin{array}{c}6,83 \pm \\
1,07\end{array}$ & $\begin{array}{c}34,80 \pm \\
3,47\end{array}$ & $\begin{array}{c}0,08 \pm \\
0,03\end{array}$ & $\begin{array}{c}5,65 \pm \\
0,6\end{array}$ & $\begin{array}{c}6,35 \pm \\
0,69\end{array}$ & $\begin{array}{c}6,71 \pm \\
0,77\end{array}$ & $\begin{array}{c}34,81 \pm \\
7,36\end{array}$ & $\begin{array}{c}0,07 \pm \\
0,01\end{array}$ \\
\hline Total & $\begin{array}{c}6,21 \pm \\
0,97\end{array}$ & $\begin{array}{c}6,84 \pm \\
1,06\end{array}$ & $\begin{array}{c}7,14 \pm \\
1,07\end{array}$ & $\begin{array}{c}31,81 \pm \\
4,94\end{array}$ & $\begin{array}{c}0,09 \pm \\
0,03\end{array}$ & $\begin{array}{c}5,95 \pm \\
0,74\end{array}$ & $\begin{array}{c}6,55 \pm \\
0,83\end{array}$ & $\begin{array}{c}6,84 \\
\pm 0,89\end{array}$ & $\begin{array}{c}31,43 \pm \\
8,28\end{array}$ & $\begin{array}{c}0,08 \pm \\
0,02\end{array}$ \\
\hline
\end{tabular}

L/LRC: Largo Bolsa cloacal / Longitud Recta de Caparazón * 100; L/Plastrón: Largo Bolsa cloacal / Longitud de Plastrón; L/SMV: Largo Bolsa cloacal / Sutura Media Ventral; AnO/An: Ancho Bolsa cloacal / Ancho animal * 100; PO/Pan: Peso Bolsa cloacal / Peso animal * 100

Tabla 11. Relación porcentual alométrica de la cloaca de la tortuga sabanera

\begin{tabular}{|c|c|c|c|c|c|}
\hline \multicolumn{7}{|c|}{ CLOACA } \\
\hline & L/LRC & L/Plastrón & L/SMV & AnO/An & PO/Pan \\
\hline+ & $36,51 \pm 6,19$ & $39,44 \pm 07$ & $40,83 \pm 7,75$ & $12,47 \pm 1,87$ & $0,59 \pm 0,08$ \\
\hline \multirow{+}{*}{} & $43,17 \pm 11,41$ & $48,31 \pm 12,13$ & $51,13 \pm 13,28$ & $5,92 \pm 1,18$ & $0,30 \pm 0,11$ \\
\hline Total & $39,84 \pm 9,34$ & $43,88 \pm 10,46$ & $45,98 \pm 11,60$ & $9,19 \pm 3,75$ & $0,44 \pm 0,18$ \\
\hline
\end{tabular}

L/LRC: Largo Cloaca / Longitud Recta de Caparazón * 100; L/Plastrón: Largo Cloaca / Longitud de Plastrón; L/SMV: Largo Cloaca / Sutura Media Ventral; AnO/An: Ancho Cloaca / Ancho animal *100; PO/Pan: Peso Cloaca / Peso animal * 100 


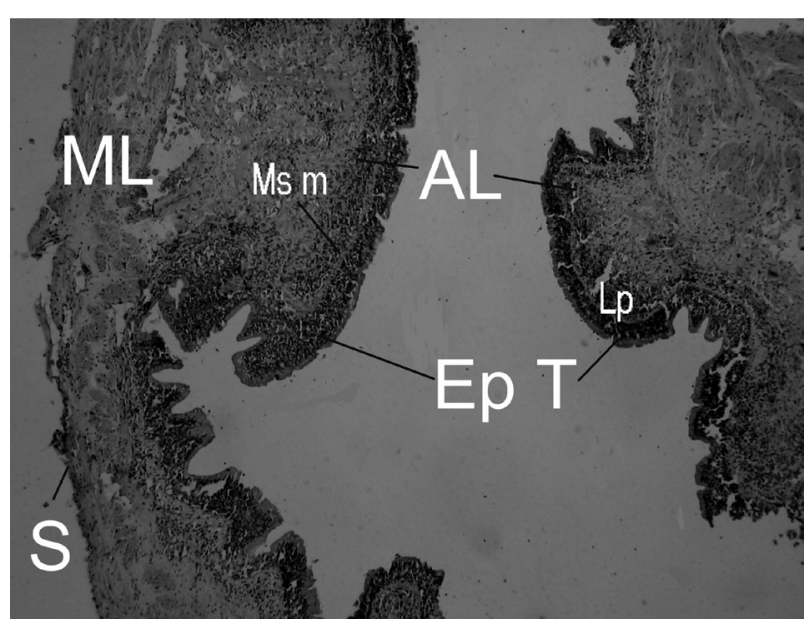

Figura 17. Corte histológico de Bolsa cloacal 4X

adyacente a esta se encuentra una gruesa capa muscular (Msc). Por último se recubre por una túnica serosa externa (Figura 18). La relación porcentual alométrica de la cloaca se observa en la tabla 11.

\section{Discusión}

Los resultados obtenidos a partir de observación, la medición, y procesamiento de las diferentes estructuras y del sistema urogenital de la especie estudiada permiten establecer de manera descriptiva y didáctica las siguientes consideraciones con respecto a lo encontrado a la literatura especializada, justificando las diferencias encontradas respecto a dicha literatura.

Las medidas del caparazón LCR de las hembras (26.47 $\mathrm{cm})$ y de los machos LRC de $(19.11 \mathrm{~cm})$ difieren de lo encontrado por Rueda y Rueda (2003), que fue de 23

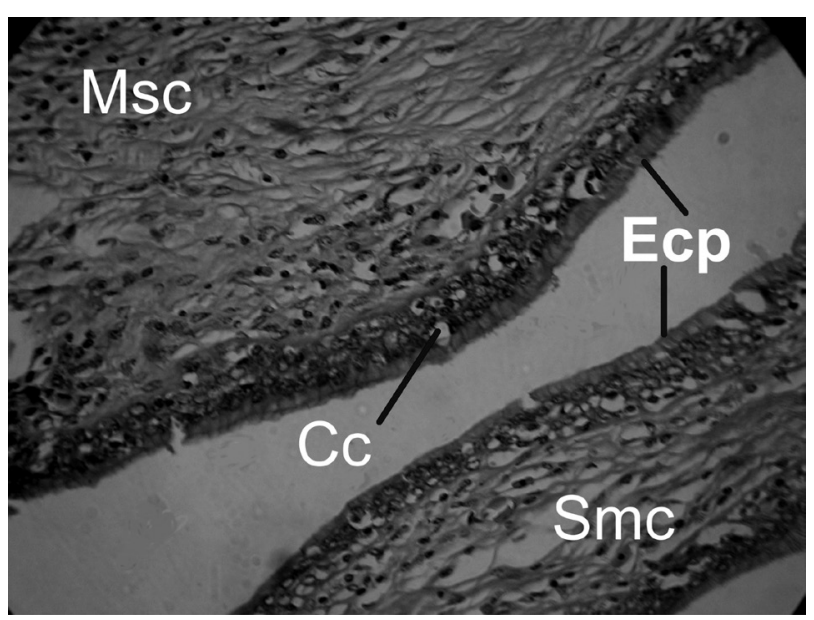

Figura 18. Corte histológico de cloaca $4 \mathrm{X}$ $\mathrm{cm}$ para las hembras y 17 para los machos. Esta diferencia se puede ser explicada por la procedencia de las muestras, y las diferentes condiciones alimenticias o medioambientales (Mader, 1996).

Los riñones topográficamente se encontraron de acuerdo a lo reportado por Wyneken, (2001); Chacón (2001) y Faria (2003) en tortugas marinas, tortuga terecay y morroco negro respectivamente. Histológicamente se encontraron asas de Henle al igual que lo descritó Faria (2003) y diferente a lo reportado por Chacón (2001) y Oros (2004), que por ser amniotas tienen riñones de tipo metanéfrico (Kardong, 1996). Adicionalmente se encontró que el tamaño de los glomérulos es pequeño y que se encuentran en poca cantidad (Chacón, 2001).

Los uréteres por ser conductos presentaron un epitelio cúbico simple similar a lo reportado por Chacón, (2001), lo cual difiere de Faria (2003), que encontró un epitelio compuesto.

En los ovarios se logró diferenciar las tecas y las células germinales (Chacón, 2001), a diferencia de lo reportado por (Romero et al., 1999) que caracterizan el estroma como septos formados por tejido conectivo, láminas elásticas y fibras musculares.

El oviducto se exhibió macroscópicamente con estriaciones, lo que no se había reportado en la literatura. A diferencia de Chacón (2001) no se encontró un útero ni espermatecas.

En los testículos se encontró una túnica albugínea similar a lo encontrado en serpientes por Al-Dokhi (2004), incrementado por el hallazgo de la células de Sertoli (Gribbins et al., 2005) al igual que las fases proliferativas descritas por esté, estas estructuras se acompañan de la células de Leyding (Al-Dokhi et al., 2004).

En el epidídimo se encontró la llegada de la red de testis, no reportada para tortugas (Oros, 2004) y el seguimiento del conducto deferente con un epitelio cúbico simple, que difiere del autor citado.

El pene presentó cinco porciones, que no fueron reportadas por Oros (2004), aunque se coincide en la identificación de la ranura uretral llamada saco espermático.

Por último las bolsas cloacales, tienen un epitelio cilíndrico simple que puede absorver agua de la cual podría extraer el oxigeno disuelto para cubrir los requerimientos bajo condiciones de apnea.

A diferencia de los trabajos realizados en otras especies de quelonios y reptiles, en los cuales se asignaban colores a los órganos (Wyneken, 2001; Chacón, 2001; 
Faria, 2003; Oros, 2004), sin hacer referencia especifica a el color exacto y sin un patrón de comparación, se asignaron los colores de los órganos a través de la utilización de la tabla patrón estandarizada por Microsoft ${ }^{\circledR}$, lo que imprime un índice de mayor confiabilidad, validez y la posibilidad de que el estudio sea replicable.

\section{Conclusiones}

Al describir las características de la anatomía e histología para los sistemas y órganos estudiados en la tortuga sabanera Podocnemis vogli se puede concluir que los hallazgos son, en su mayoría, concordantes con los resultados de estudios anteriores en reptiles. Sin embargo, fueron encontradas algunas particularidades referentes a la forma, tamaño o presencia-ausencia de algunos órganos.

Se hallaron modificaciones histológicas con relación a los reportes de la literatura para reptiles que marcan diferencias respecto a los epitelios y las túnicas estructurales en el sistema urinario, ya que las modificaciones encontradas se acercan a la forma de excreción metanefrica, con presencia de una vejiga urinaria, realizada por este tipo de animales.

A pesar de que los resultados obtenidos para la morfometría de los órganos, pueden no ser estadísticamente significativos, por el tamaño de la muestra, pueden ser tomados como valores de referencia y por ende, se convierten en una herramienta valiosa de diagnóstico de anormalidades morfológicas y fisiológicas en algún individuo de la especie.

\section{Agradecimientos}

Los autores agradecen al laboratorio de histopatología de la Universidad de los Llanos y a Cormacarena, convenio 28205-007(2) Cormacarena-Instituto de Investigaciones de la Universidad de los Llanos.

\section{Referencias}

Al-Dokhi OA, Al-Onazee YZ, Mubarak M. Light and Electron Microscopy of the Testicular Tissue of the Snake Eryx jayakari (Squamata, Reptilia) with a Reference to the Dividing Germ Cells. J Biol Sci, 2004, 4(3): 345-351.

Avendaño I. Aproximación al conocimiento sobre la reproducción de los quelonios. Universidad Nacional de Colombia. Voluntarios Urras. Boletín GEAS. 2002. En Internet: www.portalveterinaria.com/sections.php?op=viewarticle\&artid=143\#top

Banks W. Histología Veterinaria Aplicada, 1996. segunda edición Editorial Manual Moderno.
Ceballos CP. Tortugas (Testudinata) Marinas y Continentales de Colombia. Biota Colombiana. 2000; 187-194

Chacón E. Aproximación a la Descripción Macroscópica y Microscópica de los Sistemas Digestivo y Urogenital de la Terecay (Podocnemis unifilis). Tesis como trabajo de grado para optar al título de Médico Veterinario y Zootecnista. Universidad de los Llanos 2001.

Cites. Guía de identificación de las tortugas protegidas por la Convención sobre el Comercio International de Especies Amenazadas de Fauna y Flora Silvestres. Ministerio del Medio Ambiente del Canadá y de PROFEPA (SEMARNAP).1999.

Claude JA. Geometric morphometric assessment of the effects of environment and cladogenesis on the evolution of the turtle shell. The Linnean Society of London, Biol J Linn Soc, 2003, 79: 485-501

Close B. Recomendaciones para la Eutanasia de los Animales de Experimentación. University of Oxford.1995.

Crews D, Fleming A, Willingham E. Role of Steroidogenic Factor 1 and Aromatase in Temperature - Dependent Sex Determination in the Red Eared Slider Turtle. J Exp Zool, 2001; 290: 597 606.

Faria TN. Topografía e morfología do sistema urinario de jabuti "Geochelone carbonaria" (Spix, 1824). Tese (Doutorado). Universidade de Sao Paulo. 2003.

Fleming A, Wibbels T, Skipper JK. Developmental Expression of Steroidogenic Factor 1 in a Turtle with Temperature-Dependent Sex Determination. Gen Comp Endocrinol, 1999; 116: 336-346

Gribbins KM, Happ CS, Sever DM. Ultrastructure of the reproductive system of the black swamp snake (Seminatrix pygaea). V. The temporal germ cell development strategy of the testis. Acta Zoologica, 2005; 86: 223-230.

Herrel A, O'reilly JC, Richmond AM. Evolution of bite performance in turtles. J Evol Biol, 2002; 15:1083-1094.

Janeiro-Cinquini TRF, Variação anual do sistema reprodutor de fêmeas de Bothrops jararaca (Serpentes, Viperidae). Iheringia, Sér. Zool., Porto Alegre. 2004; 94(3):325-328.

Kardong K. Vertebrados, Anatomía Comparada. Función, Evolución. Mc Graw Hill - Interamericana. 1999.

Mader DR. Reptile and Medicine Surgery. WB Saunders Company, Pennsylvania. 1996.

Martínez AS. Manual Clínico de Reptiles. Barcelona España. Grass latros Ediciones. 1994.

Medem F. La reproducción de la "Icotea": (Pseudemys scripta callirostris), (Testudines Emydidae), Caldasia, 1975; 11(53): 83-101.

Moon PF, Hernández SM. Reptiles: Aquatic Turtles (Chelonians). In: Zoological Restraint and Anesthesia, Heard D. (Ed.) International Veterinary Information Service, Ithaca NY (www.ivis.org), 2001; B0118.0301

Oros J. Anatomía e Histología de Reptiles. Universidad de las palmas de la Gran Canaria. En internet: http://www5.ulpgc.es/servidores/reptilia/2004 
Pereira JG, Sousa KR, Abreu-Silva A L, Melo FA, Costa AD. Histology of the spleen of the muçuã Kinosternon scorpioides (Chelonia: Kinosternidae) Acta Microscopica, Congress of the Brazilian Society for Microscopy and Microanalysis. 2003; 12(2): pp

Pough HF. Vertebrate Life. Fifth Edition. Arizona State University West. New Jersey. 1999; 342-367.

Pritchard P. Enciclopedia of Turtles. TFH Publications, Inc. Ltd. Neptune, NJ. 1979. 895pp.

Ramírez J. Técnicas de recolección y control de calidad de huevos de tortugas y cocodrilos. Zoodivulgación, 1999; 1(1): 32

Rieppel O. Turtles as diapsid reptiles. - Zoologica Scripta.2000. $29,199-212$

Romer AS, Parsons TS. Anatomía Comparada de los Vertebrados. Mc Graw Hill. 1985; 322-327

Romero de Pérez G, Ramírez MP, Calderón ML. Estudio preliminar de la ultraestructura de la pared del ovario y de foliculos previtelogénicos y vitelogénicos tempranos de Caiman crocodilus fuscus (Reptilia, Crocodylidae). Rev Acad Colomb Cienc, 1999; 23Supl: 453-464.
Rueda JV, Rueda JN. Las tortugas y crocodylia de Colombia: Manual para su identificación. Bogotá. Ed not Pub. 2003.

Sacristán A. Fisiología Veterinaria. New York, United States of America. Editorial Mc Graw Hill.1995.

Valenzuela N, Adams DC, Janzen FJ. Pattern Does Not Equal Process: Exactly When Is Sex Environmentally Determined?. The American Naturalist, 2003; 161(4): 676-683.

Varela N. Bases de Nutrición en Fauna SilvestreFuente: Boletín GEAS. Boletín del Grupo de Estudio de Animales Silvestres. Universidad Nacional de Colombia. 2003; 5(1): pp.

Weichert CK. Elementos de Anatomía de los Cordados. $2^{\text {a }}$ Ed. México. Mc Graw Hill 1981.p307

Wyneken J. 2001. The Anatomy of Sea Turtles. U.S. Department of Commerce NOAA Technical Memorandum NMFS-SEFSC-470, 1-172 pp. 